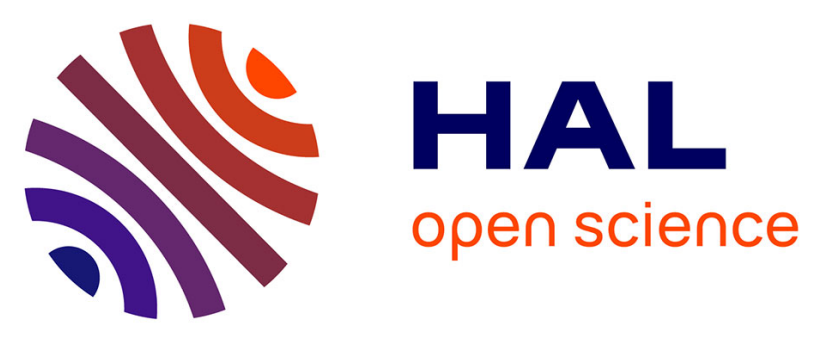

\title{
Are the absolute configurations of 2-(1-hydroxyethyl)-chromen-4-one and its 6-bromo derivative determined by X-ray crystallography correct? A vibrational circular dichroism study of their acetate derivatives
}

F. J. Devlin, P. J. Stephens, Pascale Pascale Besse, P. Besse-Hoggan

Besse-Hoggan

\section{- To cite this version:}

F. J. Devlin, P. J. Stephens, Pascale Pascale Besse, P. Besse-Hoggan Besse-Hoggan. Are the absolute configurations of 2-(1-hydroxyethyl)-chromen-4-one and its 6-bromo derivative determined by X-ray crystallography correct? A vibrational circular dichroism study of their acetate derivatives. Tetrahedron: Asymmetry, 2005, pp.1557-1566. 10.1016/j.tetasy.2005.02.033 . hal-00125725

\section{HAL Id: hal-00125725 \\ https://hal.science/hal-00125725}

Submitted on 5 Mar 2007

HAL is a multi-disciplinary open access archive for the deposit and dissemination of scientific research documents, whether they are published or not. The documents may come from teaching and research institutions in France or abroad, or from public or private research centers.
L'archive ouverte pluridisciplinaire HAL, est destinée au dépôt et à la diffusion de documents scientifiques de niveau recherche, publiés ou non, émanant des établissements d'enseignement et de recherche français ou étrangers, des laboratoires publics ou privés. 


\title{
Are the absolute configurations of 2-(1-hydroxyethyl)-chromen- 4-one and its 6-bromo derivative determined by $\mathrm{X}$-ray crystallography correct? A vibrational circular dichroism study of their acetate derivatives
}

\author{
Frank J. Devlin, ${ }^{\mathrm{a}}$ Philip J. Stephens ${ }^{\mathrm{a}, *}$ and Pascale Besse ${ }^{\mathrm{b}}$ \\ ${ }^{a}$ Department of Chemistry, University of Southern California, Los Angeles, CA 90089-0482, USA \\ ${ }^{\mathrm{b}}$ Laboratoire de Synthèse et Etude de Systèmes à Intérêt Biologique, UMR 6504 du CNRS, Université Blaise Pascal, \\ 63177 Aubière Cedex, France
}

\begin{abstract}
The vibrational circular dichroism (VCD) spectra of the acetate derivative, 3, of 2-(1-hydroxyethyl)-chromen-4-one, 1, and the acetate derivative, 4 , of 6-bromo-2-(1-hydroxyethyl)-chromen-4-one, 2 , in the $\mathrm{C}=\mathrm{O}$ stretching region are reported. Density functional theory (DFT) predictions of the VCD spectra of the $\mathrm{C}=\mathrm{O}$ stretching modes of $(R)-\mathbf{3}$ and $(R)-\mathbf{4}$ are in excellent agreement with the experimental spectra for $(+)-3$ and $(+)-4$, demonstrating that the absolute configurations of both molecules are $(R)-(+) /(S)$ $(-)$. Since acetylation of $(+)-\mathbf{1}$ and $(+)-\mathbf{2}$ yields $(+)-\mathbf{3}$ and $(+)-\mathbf{4}$, this in turn leads to $(R)-(+) /(S)-(-)$ for both $\mathbf{1}$ and $\mathbf{2}$. The absolute configurations of (-)-1 and (-)-2 were previously determined using X-ray crystallography to be $R$ and $S$, respectively. Our results lead to the conclusion that the previously reported absolute configuration of 1 is incorrect.

This work is the first to apply the 'conformational rigidification via chemical derivatisation' methodology to the determination of absolute configuration using VCD spectroscopy and illustrates its utility in determining the absolute configurations of chiral alcohols and, by extension, other classes of chiral molecules containing flexible functional groups.

(c) 2005 Elsevier Ltd. All rights reserved.
\end{abstract}

\section{Introduction}

Chiral molecules exhibit vibrational circular dichroism (VCD). ${ }^{1-5}$ Mirror-image enantiomers of a chiral molecule exhibit mirror-image VCD spectra. Consequently, VCD spectroscopy permits the determination of the absolute configuration of a chiral molecule. The application of VCD spectroscopy to the determination of absolute configurations has been made practical by the development of a quantum-mechanical theory of VCD intensities, ${ }^{6,7}$ and its implementation using ab initio density functional theory (DFT), together with gaugeinvariant (including) atomic orbitals (GIAOs). ${ }^{8,9}$ Since 1998, this DFT/GIAO methodology has been distributed via the GAUSSIAN ab initio program, ${ }^{10}$ and has been the basis for an increasing number of absolute configuration determinations using VCD..$^{3-5,11-17}$

\footnotetext{
${ }^{*}$ Corresponding author. Tel.: +1 213740 4119; fax: +1 213740 3972; e-mail: pstephen@usc.edu
}

Herein, we further demonstrate the power of the VCD technique via its application to the determination of the absolute configurations of 2-(1-hydroxyethyl)-chromen-4-one, $\mathbf{1}$, and its 6-bromo derivative, $\mathbf{2}$ :

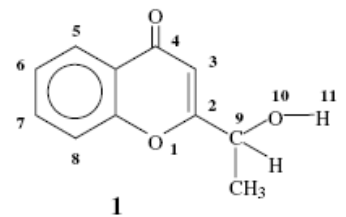<smiles>CC(O)c1cc(=O)c2cc(Br)ccc2o1</smiles>

Optically active 1 was first prepared by Besse et al. ${ }^{18}$ via the microbiological reduction of 2-acetyl-chromen-4one. The (-)-isomer of 1 was studied using X-ray crystallography and the absolute configuration determined to be $R$. In parallel, the (-)-isomer of the 6-bromo derivative of 1,2 , was also prepared and its absolute configuration determined by X-ray crystallography to be $S$. The surprising switch of the absolute configuration from 
$(R)-(-)$ for $\mathbf{1}$ to $(S)-(-)$ for $\mathbf{2}$ has led us to re-investigate the absolute configurations of these two molecules using VCD spectroscopy.

Molecules $\mathbf{1}$ and $\mathbf{2}$ are conformationally flexible due to the ability of the $-\mathrm{CH}\left(\mathrm{CH}_{3}\right) \mathrm{OH}$ group to rotate around the $\mathrm{C}-\mathrm{C}$ bond linking it to the chromen-4-one moiety (C2-C9) and, simultaneously, the ability of the $\mathrm{OH}$ group to rotate about the adjacent $\mathrm{C}-\mathrm{O}$ bond $(\mathrm{C} 9$ $\mathrm{O} 10) .1$ and 2 thus exist at room temperature as equilibrium mixtures of several conformations and their VCD spectra are the superpositions of the VCD spectra of the individual conformations. In order to simplify the analysis of the VCD spectra of $\mathbf{1}$ and $\mathbf{2}$, we have adopted a protocol, which we refer to as 'conformational rigidification via chemical derivatisation' (CRCD). ${ }^{19}$ The idea is very simple: the $\mathrm{OH}$ group of the $-\mathrm{CH}\left(\mathrm{CH}_{3}\right) \mathrm{OH}$ moiety is derivatised to form $-\mathrm{CH}\left(\mathrm{CH}_{3}\right) \mathrm{OX}$, where $\mathrm{X}$ is a much bulkier group than $\mathrm{H}$. By virtue of the greater steric hindrance to internal rotation caused by the derivatisation, conformational flexibility is reduced, that is, the number of thermally accessible conformations is smaller than in the parent molecule. We have recently demonstrated the viability of this approach in the case of chiral alcohols via studies of the acetate, tert-butyl and trimethyl-silyl derivatives of endo-borneol. ${ }^{19}$ Here, it is applied to the molecules $\mathbf{1}$ and $\mathbf{2}$, using their acetate derivatives, $\mathbf{3}$ and $\mathbf{4}$.
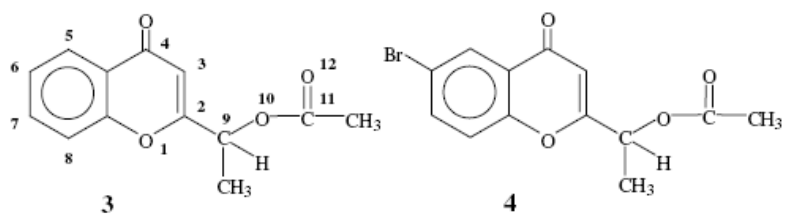

A further benefit of replacing the $\mathrm{OH}$ groups of $\mathbf{1}$ and $\mathbf{2}$ by the $\mathrm{OCOCH}_{3}$ groups of $\mathbf{3}$ and $\mathbf{4}$ is the introduction of an additional $\mathrm{C}=\mathrm{O}$ stretching vibrational mode. Typically, $\mathrm{C}=\mathrm{O}$ stretching modes of organic molecules are at $\geqslant 1650 \mathrm{~cm}^{-1}$ and are well-resolved from the other midinfrared (IR) modes, generally at $\leqslant 1600 \mathrm{~cm}^{-1}$. Thus, the $\mathrm{C}=\mathrm{O}$ stretching modes are easily assigned and their contributions to IR and VCD spectra measurable without the complication of overlapping contributions from other modes nearby. As will be demonstrated below, the $\mathrm{C}=\mathrm{O}$ stretching modes of $\mathbf{3}$ and $\mathbf{4}$ are well-resolved, easily assigned and give well-defined VCD, permitting our analysis of the absolute configurations of $\mathbf{3}$ and $\mathbf{4}$ to be convincingly based on these modes alone.

Lastly, the derivatisation of the $\mathrm{OH}$ groups of $\mathbf{1}$ and $\mathbf{2}$ removes inter-molecular hydrogen $(\mathrm{H})$-bonding and, as a result, aggregation at the concentrations used in measuring VCD spectra. The VCD spectra calculated for isolated molecules can then be meaningfully compared to experimental VCD data.

\section{Results}

The experimental IR and VCD spectra of $\mathbf{3}$ and $\mathbf{4}$ in the $\mathrm{C}=\mathrm{O}$ stretching region are shown in Figure 1. For both
3 and 4, strong bands are observed in the IR spectrum at $\sim 1665$ and $\sim 1755 \mathrm{~cm}^{-1}$, which can be assigned to $\mathrm{C}=\mathrm{O}$ stretching modes. VCD is observed corresponding to these bands. The VCD of (+)-3 and (+)-4 are qualitatively identical and quantitatively very similar.

Analysis of these spectra begins with the conformational analysis of $\mathbf{3}$ and $\mathbf{4}$. A potential energy surface (PES) scan, varying the two dihedral angles O1C2C9O10 and $\mathrm{C} 2 \mathrm{C} 9 \mathrm{O} 10 \mathrm{C} 11$, was carried out using DFT at the B3LYP/6-31G* level for $(R)-3$. [Note that the C9O10C11O12 moiety is cis; the trans conformation is significantly higher in energy. $\left.{ }^{16}\right]$ The PES obtained is shown in Figure 2, together with the corresponding PES of the parent molecule, $(R)-1^{25}$

In the case of 1 there are eight stable conformations, ah, with energies $<3 \mathrm{kcal} / \mathrm{mol}$ above the global minimum. In the case of $\mathbf{3}$, the number of stable conformations with energies $<3 \mathrm{kcal} / \mathrm{mol}$ above the global minimum is reduced to 3 , a-c. Thus, as in the case of endo-borneol, ${ }^{19}$ conversion of $\mathbf{1}$ to its acetate derivative $\mathbf{3}$ is accompanied by substantial rigidification. Optimisation of the geometries of conformations $\mathbf{3 a}-\mathbf{c}$ at the $\mathrm{B} 3 \mathrm{LYP} / 6-31 \mathrm{G}^{*}$, B3LYP/TZ2P and B3PW91/TZ2P levels led to their equilibrium geometries and energies. Their B3LYP/ TZ2P structures are illustrated in Figure 3. Key dihedral angles for the B3LYP/TZ2P and B3PW91/TZ2P geometries are given in Table 1. The B3LYP and B3PW91 functional gave very similar results: differences in corresponding dihedral angles are $<2^{\circ}$. The conformations $3 \mathrm{a}-\mathbf{c}$ differ in the dihedral angle $\mathrm{O} 1 \mathrm{C} 2 \mathrm{C} 9 \mathrm{O} 10$ and are interconverted by $\sim 120^{\circ}$ rotations about the $\mathrm{C} 2 \mathrm{C} 9$ bond. The dihedral angle C2C9O10C11 is very similar in the three conformations. The B3LYP/TZ2P and B3PW91/TZ2P relative energies of conformations a-c are given in Table 2. That the structures obtained for a-c correspond to stable conformations was verified by the calculation of their vibrational frequencies, which simultaneously permits their free energies to be obtained. The relative free energies are also given in Table 2. The B3LYP and B3PW91 functionals give very similar energies and free energies: the largest difference is $0.11 \mathrm{kcal} / \mathrm{mol}$. Conformation a is the lowest in both energy and free energy. The relative energies and free energies are very similar for both conformations $\mathbf{b}$ and $\mathbf{c}$. Since all three conformations are within $1 \mathrm{kcal} / \mathrm{mol}$ in energy and free energy, all are expected to be significantly populated at room temperature. Equilibrium populations at $293 \mathrm{~K}$ obtained from relative free energies are given in Table 2.

In the case of the 6-bromo derivative of $\mathbf{3 , 4}$, we have obtained the B3LYP/TZ2P and B3PW91/TZ2P geometries and energies of conformations a-c, starting from the optimised geometries of $(R)-3$ and replacing the $6-\mathrm{H}$ by $\mathrm{Br}$. Key dihedral angles of the resulting structures of $(R)-\mathbf{4}$ are given in Table 1. Relative energies, free energies and equilibrium populations are given in Table 2. 6- $\mathrm{Br}$ substitution is a minor perturbation on the conformational geometries and energies. The largest change in dihedral angle is $0.4^{\circ}$. The largest change in energy or free energy is $0.2 \mathrm{kcal} / \mathrm{mol}$. 

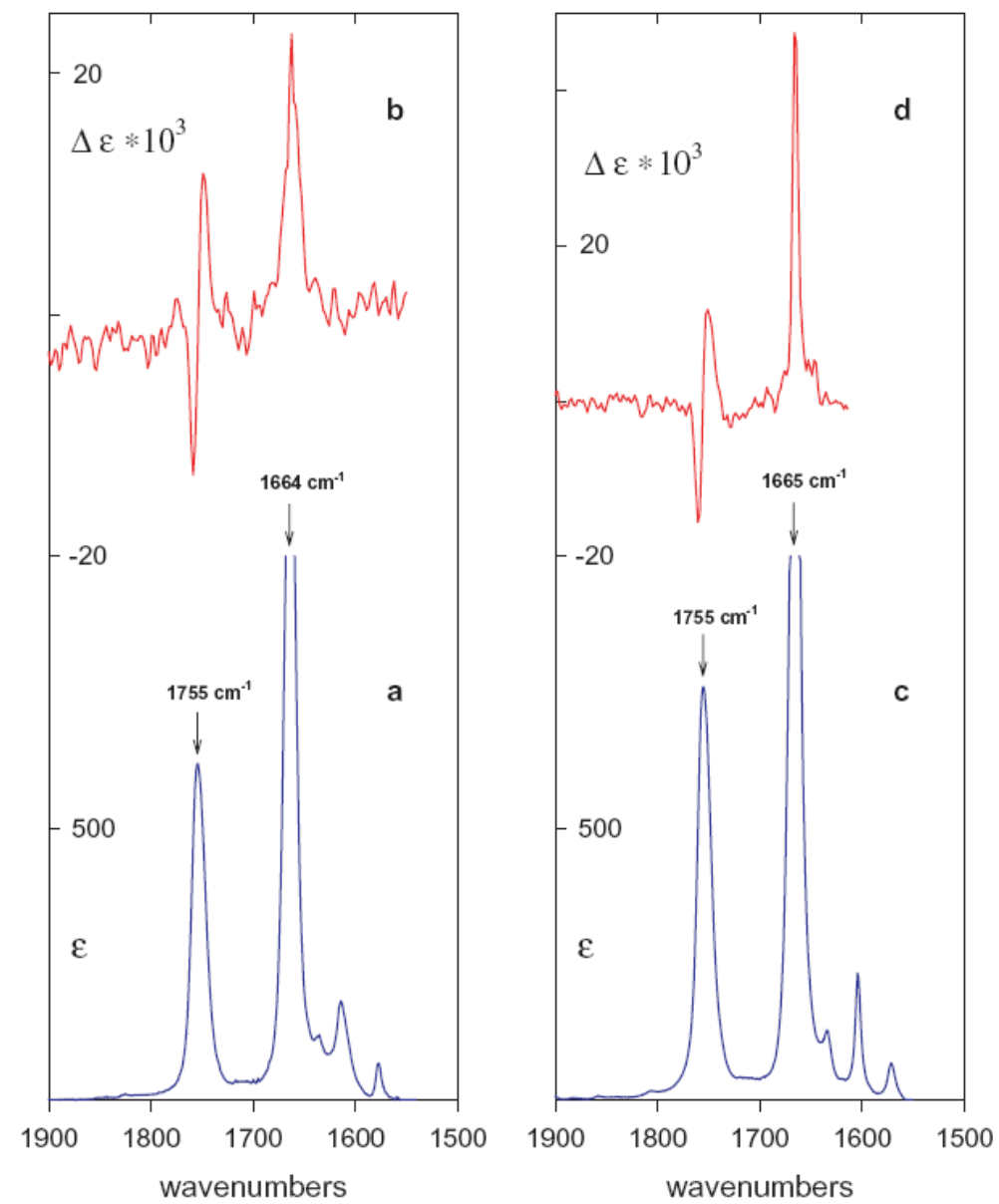

Figure 1. Experimental IR and VCD spectra of 3 and 4 in $\mathrm{CCl}_{4}$ solution in the $\mathrm{C}=\mathrm{O}$ stretching region. (a) IR: (-)-3, (b) VCD: (+)-3, (c) IR: (-)-4, (d) VCD: (+)-4.

Harmonic vibrational dipole strengths, which determine IR intensities, and rotational strengths, which determine VCD intensities, were calculated simultaneously with the harmonic vibrational frequencies for the conformations a-c of $(R)-3$ and $(R)-4$ at the B3LYP/TZ2P and B3PW91/TZ2P levels. For modes in the $\mathrm{C}=\mathrm{O}$ stretching region, the results are given in Table 3 . IR and VCD spectra were obtained thence, using the populations, given in Table 2, of the individual conformations obtained from their calculated relative free energies. The conformationally averaged spectra are shown in Figures 4 and 5. For the B3LYP/TZ2P calculations, the individual contributions of conformations $\mathbf{a}, \mathbf{b}$ and $\mathbf{c}$ are also shown.

The B3LYP/TZ2P frequencies of the $\mathrm{C}=\mathrm{O}$ stretching modes, 68 and 69 , of $\mathbf{3}$ in conformations a-c are very similar. The ranges are 2 and $6 \mathrm{~cm}^{-1}$ for modes 68 and 69 , respectively. Thus, with the line-width used $\left(\gamma=4 \mathrm{~cm}^{-1}\right)$, in the conformationally averaged B3LYP/TZ2P IR spectrum (Fig. 4a) the modes of the individual conformations are not resolved. This is also the case for modes 65-67, which are predicted in the range $1600-1700 \mathrm{~cm}^{-1}$. Comparison of the $\mathrm{B} 3 \mathrm{LYP} /$ TZ2P IR spectrum of $\mathbf{3}$ to the experimental IR spectrum leads straightforwardly to the assignment of the latter, as shown in Figure 4a. The agreement of the calculated and experimental spectra is excellent. The assignment of the $\mathrm{C}=\mathrm{O}$ stretching modes is unambiguous.

The B3LYP/TZ2P rotational strengths of the $\mathrm{C}=\mathrm{O}$ stretching modes 69 of the three conformations a-c of $(R)-\mathbf{3}$ vary in sign: in $\mathbf{3} \mathbf{a}$ the sign is negative, in $\mathbf{3} \mathbf{b}$ and $3 \mathbf{c}$ the signs are positive. As a result of the differences in frequency of mode 69 among conformations a-c, with the line-width used $\left(\gamma=4 \mathrm{~cm}^{-1}\right)$, the conformationally averaged B3LYP/TZ2P VCD spectrum of mode 69 exhibits a bisignate feature (Fig. 4b), the negative, high-frequency component arising from conformation a and the positive, low-frequency component arising from conformations $\mathbf{b}$ and $\mathbf{c}$. For $\mathrm{C}=\mathrm{O}$ stretching modes 68 , rotational strengths also vary in sign with conformation: in $\mathbf{3} \mathbf{a}$ and $\mathbf{3 b}$, the sign is positive, in $\mathbf{3} \mathbf{c}$ it is negative. For these modes the variation in frequency is less than for modes 69 . As a result, with the line-width used, the conformationally averaged VCD spectrum of mode 68 is monosignate: specifically, positive. Comparison of the B3LYP/TZ2P VCD spectrum for modes 68 and 69 to the experimental VCD for (+)-3 of the bands assigned to these two modes, shown in Figure 4b, exhibits perfect qualitative agreement between theory and experiment. It follows immediately and unambiguously that the absolute configuration of $\mathbf{3}$ is $(R)-(+)$. 


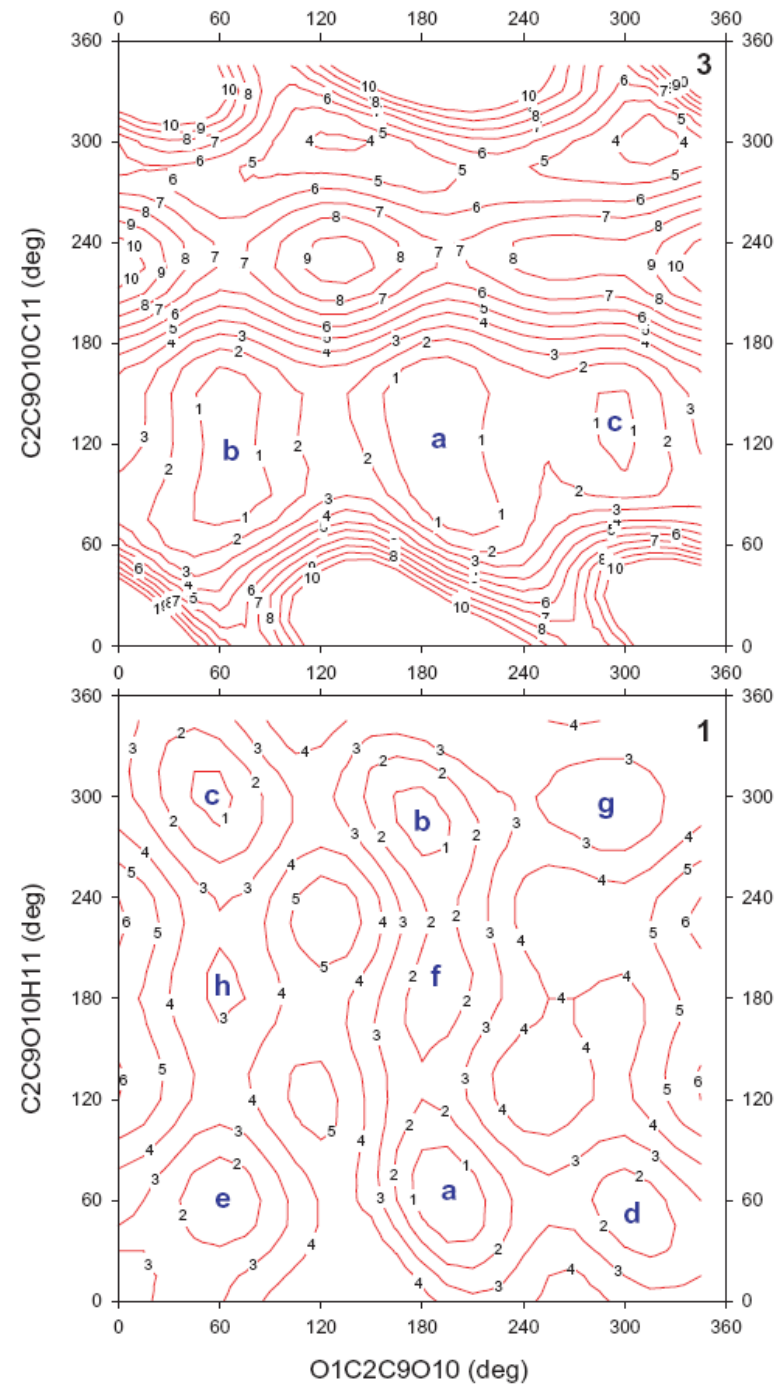

Figure 2. B3LYP/6-31G* potential energy surfaces of $(R)-1$ and $(R)-3$. Contour spacing is $1 \mathrm{kcal} / \mathrm{mol}$.

The B3LYP/TZ2P frequencies of the $\mathrm{C}=\mathrm{O}$ stretching modes 69 and 70 of the three conformations of 4 are extremely close to the frequencies of modes 68 and 69 of 3 . The maximum difference is $3 \mathrm{~cm}^{-1}$. Dipole strengths for $\mathbf{3}$ and $\mathbf{4}$ are also very similar. As a result, the conformationally averaged $\mathrm{C}=\mathrm{O}$ stretching $\mathrm{B} 3 \mathrm{LYP} / \mathrm{TZ} 2 \mathrm{P}$ IR spectrum of 4 (Fig. 5a) is qualitatively identical and quantitatively very similar to that of $(R)-3$. Comparison to the experimental IR spectrum of 4 (Fig. 5a), which is very similar to that of $\mathbf{3}$, leads to assignment of modes 69 and 70.

The B3LYP/TZ2P rotational strengths of modes 69 and 70 of the conformations a $\mathbf{c}$ of $(R)-\mathbf{4}$ are very similar to those of modes 68 and 69 of $(R)-3$. As a result, the conformationally averaged $\mathrm{C}=\mathrm{O}$ stretching VCD spectrum of $(R)-4$ (Fig. 5b) is qualitatively identical and quantitatively very similar to that of $(R)-3$. Comparison of the spectrum of $(R)-4$ for modes 69 and 70 to the experimen- tal VCD for (+)-4 of the bands assigned to these two modes, shown in Figure $5 b$, exhibits perfect qualitative agreement between theory and experiment, leading to the unambiguous conclusion that the absolute configuration of $\mathbf{4}$ is $(R)-(+)$.

Qualitatively, the B3PW91/TZ2P $\mathrm{C}=\mathrm{O}$ stretching frequencies, dipole strengths and rotational strengths of 3 and 4 are identical to the B3LYP/TZ2P parameters. As a result, the B3PW91/TZ2P IR and VCD spectra of 3 and $\mathbf{4}$ are qualitatively identical to the B3LYP/ TZ2P spectra and lead to identical analysis of the experimental IR and VCD spectra of $\mathbf{3}$ and $\mathbf{4}$. In particular, the absolute configurations of $\mathbf{3}$ and $\mathbf{4}$ deduced from comparison of B3PW91/TZ2P and experimental VCD spectra are the same. Quantitatively, B3PW91/TZ2P frequencies are somewhat higher than B3LYP/TZ2P frequencies and the deviation from experimental frequencies is greater.

\section{Discussion}

Alcohols $\mathbf{1}$ and $\mathbf{2}$ are conformationally flexible. A PES scan for 1 using DFT at the B3LYP/6-31G* level identifies eight stable conformations. The experimental VCD spectrum of $\mathbf{1}$ is thus the superposition of the individual VCD spectra of the eight conformers, each weighted by its equilibrium population. Despite the high accuracy of DFT calculations of VCD spectra, analysis of a VCD spectrum of such complexity is challenging. Consequently, the determination of the absolute configuration of 1 from its VCD spectrum is not straightforward.

The strategy of 'conformational rigidification via chemical derivatisation', which we have recently enunciated, ${ }^{19}$ is of major assistance in this situation. A PES scan of the acetate derivative of 1,3 , shows that the substitution of the $\mathrm{H}$ atom of the $\mathrm{OH}$ group by the $\mathrm{COCH}_{3}$ group substantially reduces the conformational flexibility. The number of stable conformations is reduced to three. Analogous conformational rigidification was observed in going from endo-borneol to its acetate derivative. ${ }^{19}$ The VCD spectrum of $\mathbf{3}$ is therefore the superposition of the VCD spectra of only three conformations and, consequently, much less complex than that of $\mathbf{1}$. The determination of the absolute configuration of $\mathbf{1}$ is thus greatly facilitated by the use of the acetate derivative, $\mathbf{3}$, instead of the parent alcohol, 1.

Herein, we report the analysis of the VCD spectrum of $\mathbf{3}$ over a limited spectral range: specifically, the $\mathrm{C}=\mathrm{O}$ stretching region. In addition to the $\mathrm{C}=\mathrm{O}$ stretch mode of the chromen-4-one moiety, already present in 1 , the acetate group of $\mathbf{3}$ adds a second $\mathrm{C}=\mathrm{O}$ stretch mode. We have found that these two $\mathrm{C}=\mathrm{O}$ stretch modes are both well-resolved from the bulk of the mid-IR fundamentals of $\mathbf{3}$ and well resolved from each other, and that they exhibit well-defined VCD. Their VCD therefore permits the absolute configuration of $\mathbf{3}$ to be deduced.

The initial step in the analysis is the assignment of the $\mathrm{C}=\mathrm{O}$ stretch bands in the experimental IR spectrum. 


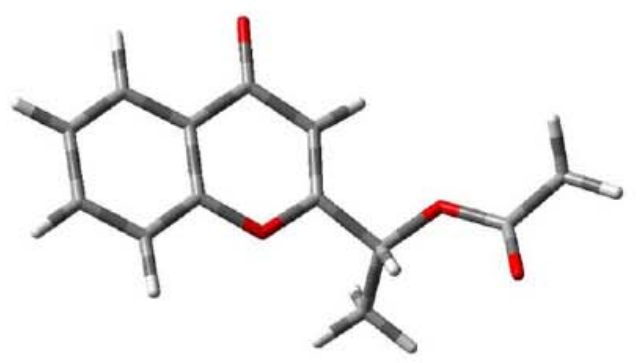

3a

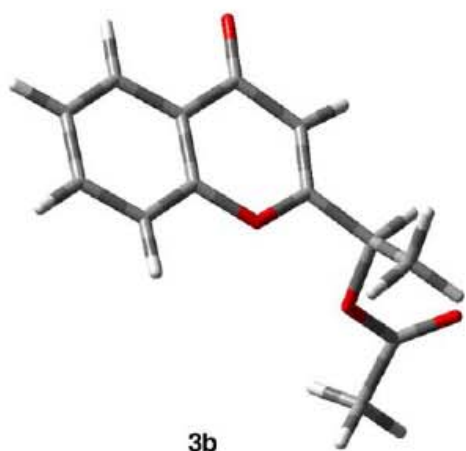

$3 b$

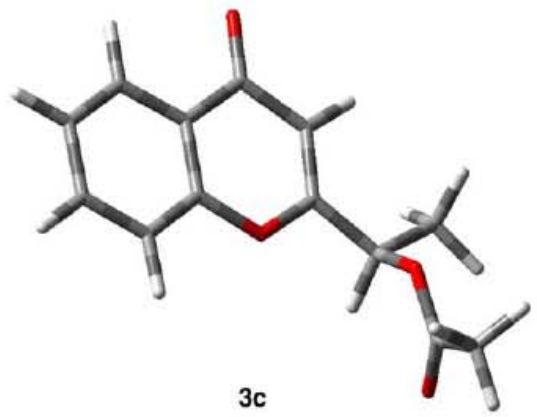

Figure 3. B3LYP/TZ2P geometries for the $R$ absolute configurations of conformations a, b and $\mathbf{c}$ of 3 .

Table 1. TZ2P dihedral angles of the conformations of 3 and 4

\begin{tabular}{crrrll}
\hline & \multicolumn{2}{c}{ O1C2C9O10 } & & \multicolumn{2}{c}{ C2C9O10C11 } \\
\cline { 2 - 3 } \cline { 5 - 6 } & B3LYP & B3PW91 & & B3LYP & B3PW91 \\
\hline 3a & -172.2 & -172.4 & & 144.5 & 143.2 \\
3b & 65.2 & 64.6 & & 146.0 & 145.2 \\
3c & -66.3 & -65.1 & & 139.0 & 137.9 \\
4a & -172.4 & -172.5 & & 144.1 & 142.8 \\
4b & 65.0 & 64.4 & & 145.9 & 145.1 \\
4c & -66.4 & -65.2 & & 139.0 & 137.5 \\
\hline
\end{tabular}

${ }^{\text {a }}$ Angles are in degrees. Absolute configuration is $R$.

Table 2. TZ2P relative energies and free energies, and populations of the conformations of 3 and 4

\begin{tabular}{|c|c|c|c|c|c|c|}
\hline & \multicolumn{2}{|c|}{$\Delta E^{\mathrm{a}}$} & \multicolumn{2}{|c|}{$\Delta G^{\mathrm{a}}$} & \multicolumn{2}{|c|}{$P(\%)^{\mathrm{b}}$} \\
\hline & B3LYP & B3PW91 & B3LYP & B3PW91 & B3LYP & B3PW91 \\
\hline 3a & 0.00 & 0.00 & 0.00 & 0.00 & 57.4 & 55.0 \\
\hline $3 b$ & 0.27 & 0.34 & 0.49 & 0.48 & 24.6 & 24.1 \\
\hline $3 \mathrm{c}$ & 0.61 & 0.60 & 0.68 & 0.57 & 18.0 & 20.9 \\
\hline $4 a$ & 0.00 & 0.00 & 0.00 & 0.00 & 52.9 & 50.1 \\
\hline $4 b$ & 0.32 & 0.38 & 0.33 & 0.28 & 30.0 & 30.8 \\
\hline $4 c$ & 0.60 & 0.59 & 0.66 & 0.56 & 17.0 & 19.1 \\
\hline
\end{tabular}

${ }^{\mathrm{a}} \Delta E$ and $\Delta G$ are in $\mathrm{kcal} / \mathrm{mol}$.

${ }^{\mathrm{b}}$ Populations are based on $\Delta G$ values; $T=293 \mathrm{~K}$.

As is usual in our work, ${ }^{3-5,11-17}$ we predicted IR and VCD spectra using DFT, the functionals B3LYP and B3PW91, and the TZ2P basis set. The accuracy of calculations at this level are well documented. ${ }^{3-5,8,9,11-17,19,23,24,26-32}$ The B3LYP and B3PW91 functionals gave very similar results for the $\mathrm{C}=\mathrm{O}$ stretching modes of $\mathbf{3}$, showing that there is minor sensitivity to the choice of functional (within the category of hybrid functionals). The three conformations a $\mathbf{c}$ exhibit very similar $\mathrm{C}=\mathrm{O}$ stretching frequencies. For the acetate $\mathrm{C}=\mathrm{O}$ stretch (mode 69) the conformational splitting is $6 \mathrm{~cm}^{-1}$ at both B3LYP and B3PW91 levels. For the chromen-4-one $\mathrm{C}=\mathrm{O}$ stretch (mode 68 ) the splittings are less: 2 and $3 \mathrm{~cm}^{-1}$. Given line-widths commensurate with the experimental line-widths, conformational splittings are predicted to be unresolved. The predicted spectra lead to unambiguous assignment of the bands at 1755 and $1664 \mathrm{~cm}^{-1}$ in the experimental IR spectrum to the acetate and chromen-4-one $\mathrm{C}=\mathrm{O}$ stretch modes, respectively. The frequency difference between the predicted and experimental frequencies is $2-3 \%$, with predicted frequencies being higher; this difference is principally due to the absence of anharmonicity in the DFT calculations. ${ }^{33}$

For each of the $\mathrm{C}=\mathrm{O}$ stretching modes, the three conformations of 3 exhibit rotational strengths varying in both sign and magnitude. The sensitivity of VCD spectra to conformational structure in conformationally flexible molecules is well precedented and unsurprising. ${ }^{3-5,11-17,19,26-32}$ The VCD of each of the two $\mathrm{C}=\mathrm{O}$ stretching modes is then a superposition of three contributions, differing in frequency and in sign. In the case of the acetate $\mathrm{C}=\mathrm{O}$ stretch modes, because of the larger conformational frequency splitting the net VCD predicted is bisignate. In the case of the chromen-4-one $\mathrm{C}=\mathrm{O}$ stretch modes, the frequency splitting is smaller and the predicted net VCD is monosignate. The predicted $\mathrm{C}=\mathrm{O}$ stretching $\mathrm{VCD}$ is qualitatively identical and quantitatively very similar for the B3LYP and B3PW91 spectra, showing that the predicted spectra 
Table 3. Harmonic frequencies, dipole strengths and rotational strengths for the $\mathrm{C}=\mathrm{O}$ stretching modes of 3 and $4^{\mathrm{a}}$

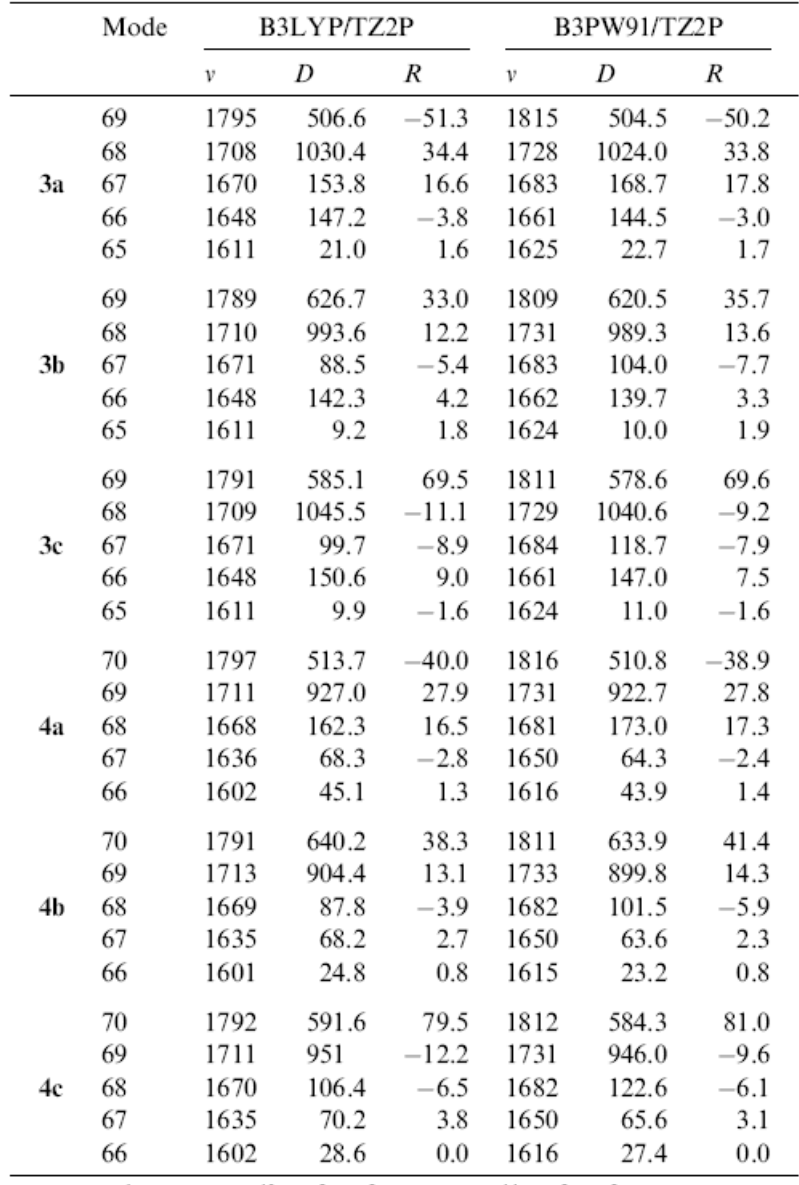

a $v$ in $\mathrm{cm}^{-1}, D$ in $10^{-40} \mathrm{esu}^{2} \mathrm{~cm}^{2}, R$ in $10^{-44} \mathrm{esu}^{2} \mathrm{~cm}^{2}$. Absolute configuration is $R$.

are insensitive to the choice of functional. The experimental VCD of the $\mathrm{C}=\mathrm{O}$ stretching modes of $(+)-3$ is bisignate for the acetate $\mathrm{C}=\mathrm{O}$ stretch at $1755 \mathrm{~cm}^{-1}$ and monosignate for the chromen-4-one $\mathrm{C}=\mathrm{O}$ stretch at $1664 \mathrm{~cm}^{-1}$. With respect to sign, the experimental VCD of both $\mathrm{C}=\mathrm{O}$ stretch modes for $(+)-3$ is perfectly reproduced by the calculated VCD spectra of $R-3$. It follows immediately that the absolute configuration of 3 is $(R)-(+) /(S)-(-)$.

The determination of the absolute configuration of the acetate derivative, $\mathbf{4}$, of the $6-\mathrm{Br}$ derivative of $\mathbf{1 , 2}$, was carried out in parallel, using the same methodology. In all respects, the 6-Br substitution of 3 is a minor perturbation. Both experimentally and theoretically the IR and VCD spectra of the $\mathrm{C}=\mathrm{O}$ stretch modes of $\mathbf{3}$ and $\mathbf{4}$ are nearly superposable. Again, identity with respect to sign of the $\mathrm{C}=\mathrm{O}$ stretching VCD is found when the predicted spectrum for $(R)-\mathbf{4}$ is compared to the experimental spectrum for (+)-4, leading unambiguously to the absolute configuration for 4 of $(R)-(+) /(S)-(-)$.

The parent alcohols $(+)-\mathbf{1}$ and $(+)-\mathbf{2}$ led to acetate derivatives (+)-3 and (+)-4; that is, the derivatisation does not change the sign of $[\alpha]_{\mathrm{D}}$. Likewise, $(R)-1$ and $(R)-2$ give
$(R)-3$ and $(R)-4$. It therefore follows that the absolute configurations of $\mathbf{1}$ and $\mathbf{2}$ are identical to those of $\mathbf{3}$ and 4: $(R)-(+) /(S)-(-)$. Our conclusions are consistent with the prior assignment of the absolute configuration of 2 as $(R)-(+) /(S)-(-)$ using X-ray crystallography, ${ }^{18}$ but inconsistent with the assignment of the absolute configuration of $\mathbf{1}$ as $(R)-(-) /(S)-(+) .{ }^{18}$ We conclude that in the case of the molecule 2, containing a heavy atom $(\mathrm{Br}), \mathrm{X}$-ray crystallography successfully assigned the absolute configuration, while in the case of molecule 1, with no heavy atom, X-ray crystallography yielded an incorrect absolute configuration.

It should be noted that, irrespective of the DFT/GIAO analysis of the VCD spectra of $\mathbf{3}$ and $\mathbf{4}$, the near-superposability of the experimental VCD of the $\mathrm{C}=\mathrm{O}$ stretching modes of (+)-3 and (+)-4 renders the possibility that their absolute configurations are opposite exceedingly remote.

In addition, as will be reported elsewhere, ${ }^{34}$ the analysis of the VCD spectra of $\mathbf{3}$ and $\mathbf{4}$ in the mid-IR spectral range below the $\mathrm{C}=\mathrm{O}$ stretching frequencies confirms the absolute configurations arrived at here, as does analysis of the VCD spectra of the tert-butyl derivatives of $\mathbf{1}$ and $\mathbf{2}$, which are even more conformationally rigid than 3 and 4.

At the present time, we have no detailed explanation for the erroneous outcome of the X-ray crystallographic study of the absolute configuration of 1 . (Note that values of the Flack parameter ${ }^{35,36}$ were not reported in Ref. 18.) Our results do suggest that the absolute configurations of molecules lacking heavy atoms should be confirmed by other methods before being accepted as definitive.

\section{Conclusion}

Our study of the absolute configurations of $\mathbf{3}$ and $\mathbf{4}$ further illustrates the utility of VCD spectroscopy in determining the absolute configurations of organic molecules ${ }^{3-5,11-17}$ and provides the first example of the application of the CRCD methodology in conjunction with VCD. We anticipate that CRCD will greatly facilitate the determination of the absolute configurations of chiral molecules containing conformationally flexible functional groups in future applications of VCD spectroscopy.

Alcohols typically aggregate at the concentrations used in VCD measurements via inter-molecular hydrogen bonding of their $\mathrm{OH}$ groups. VCD spectra can be sensitive to aggregation. ${ }^{37,38}$ Derivatisation of alcohols has the added benefit that such aggregation is eliminated. VCD calculations for isolated molecules can be meaningfully compared to experimental VCD data. Herein, we have confirmed the expectation that aggregation of 3 and $\mathbf{4}$ does not occur in $\mathrm{CCl}_{4}$ solutions by measuring their IR spectra over the concentration range 0.001$0.1 \mathrm{M}$. The spectra accurately obeyed Beer's Law over this range. 

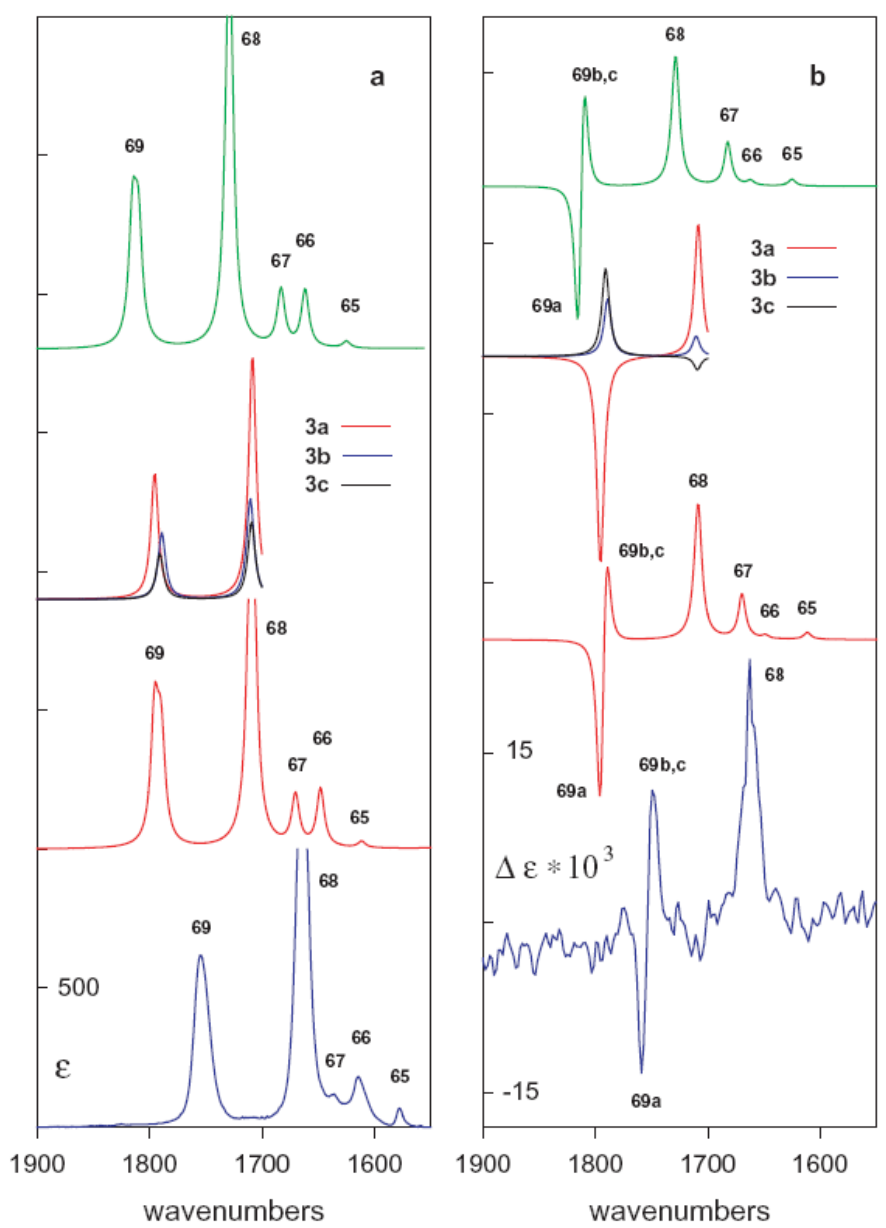

Figure 4. (a) Comparison of the conformationally averaged B3LYP/TZ2P (red) and the B3PW91/TZ2P (green) IR spectra of 3 to the experimental IR spectrum of (-)-3 (blue) (from Fig. 1). (b) Comparison of the conformationally averaged B3LYP/TZ2P (red) and the B3PW91/TZ2P (green) VCD spectra of $(R)-3$ to the experimental VCD spectrum of (+)-3 (blue) (from Fig. 1). The population-weighted B3LYP/TZ2P IR and VCD spectra for each conformer $3 \mathrm{a}-\mathbf{3} \mathbf{c}$ are also shown. Fundamentals are numbered. Line shapes in calculated spectra are Lorentzian $\left(\gamma=4 \mathrm{~cm}^{-1}\right)$.

\section{Experimental}

\subsection{Analytical methods}

For ${ }^{1} \mathrm{H}(400.13 \mathrm{MHz})$ and ${ }^{13} \mathrm{C}(100.61 \mathrm{MHz})$ NMR spectra, the chemical shifts were relative to chloroform. Optical rotations were determined on a JASCO polarimeter. Microanalyses were performed by the Service Central d'Analyses du CNRS, Vernaison, France. Enantiomeric excesses of $\mathbf{1}$ and $\mathbf{2}$ were determined via HPLC using a Chiralcel OB column at room temperature, $\lambda=254 \mathrm{~nm}$, cyclohexane/isopropanol 95/5, 0.1 $\mathrm{mL} / \mathrm{min}$ for 1 ; cyclohexane/isopropanol $99 / 10.45 \mathrm{~mL} /$ $\min$ for 2 .

\subsection{Synthesis of substrates}

The syntheses of the substrates for microbiological reduction, 2-acetyl-chromen-4-one and 2-acetyl-6-bromo-chromen-4-one, has been already described in the literature. ${ }^{18,20}$

\subsection{Microbiological reduction}

Freeze-dried Baker's yeast is a commercial product (Vahine, Monteux, France). Freeze-dried Baker's yeast $(1 \mathrm{~g})$ was placed in a $500 \mathrm{~mL}$ conical flask with $50 \mathrm{~mL}$ of distilled water and $50 \mathrm{mg}$ of substrate. Bioconversions with Yamadazyma farinosa IFO 10896 were performed with resting cells previously grown at $27^{\circ} \mathrm{C}$ in the following medium: glucose $50 \mathrm{~g}$; tryptone (Difco) $7 \mathrm{~g}$; yeast extract $5 \mathrm{~g} ; \mathrm{K}_{2} \mathrm{HPO}_{4} 2 \mathrm{~g} ; \mathrm{KH}_{2} \mathrm{PO}_{4} 3 \mathrm{~g}$ and $\mathrm{H}_{2} \mathrm{O} 1 \mathrm{~L}$; preculture and culture: $48 \mathrm{~h}$. After culture, the microorganism was centrifuged, and then washed twice with phosphate buffer $\left(\mathrm{Na}_{2} \mathrm{HPO}_{4} \cdot 12 \mathrm{H}_{2} \mathrm{O} \quad 10.75 \mathrm{~g} ; \mathrm{NaH}_{2}-\right.$ $\mathrm{PO}_{4} \cdot 2 \mathrm{H}_{2} \mathrm{O} 10.95 \mathrm{~g}$ and $\mathrm{H}_{2} \mathrm{O} 1 \mathrm{~L}$ ). Mycelium ( $10 \mathrm{~g}$ ) was added in a $100 \mathrm{~mL}$ bottle containing $3 \mathrm{~g}$ glucose, $200 \mathrm{mg}$ of substrate and $60 \mathrm{~mL}$ phosphate buffer closed with a septum. The bioconversion reaction was carried out under anaerobic conditions $\left(\mathrm{N}_{2}\right.$ atmosphere) according to Ohta and co-workers. ${ }^{21,22}$ After 24 or $48 \mathrm{~h}$ of incubation at $27^{\circ} \mathrm{C}$ on a rotating table set at $200 \mathrm{rpm}$, the mixture was centrifuged for $10 \mathrm{~min}$ at 

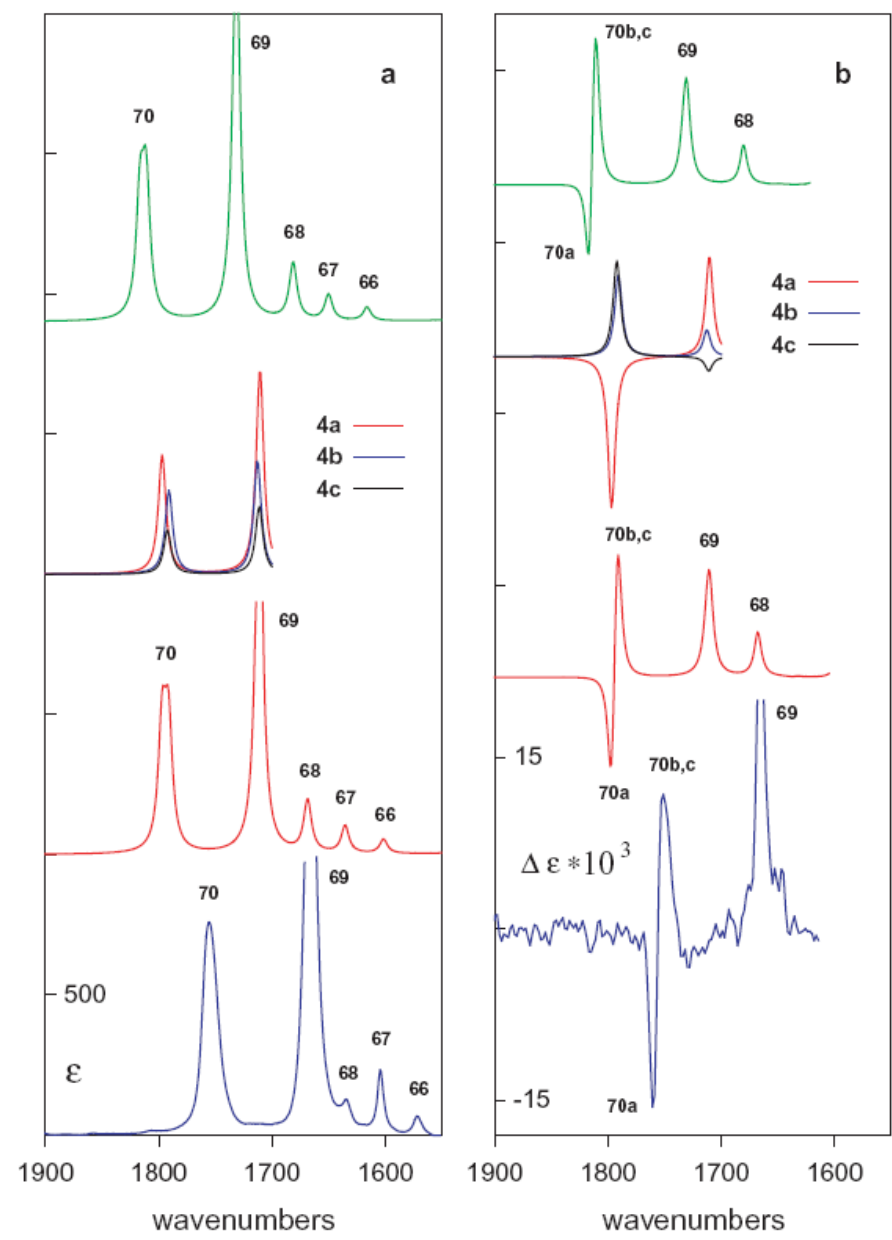

Figure 5. (a) Comparison of the conformationally averaged B3LYP/TZ2P (red) and the B3PW91/TZ2P (green) IR spectra of 4 to the experimental IR spectrum of (-)-4 (blue) (from Fig. 1). (b) Comparison of the conformationally averaged B3LYP/TZ2P (red) and the B3PW91/TZ2P (green) VCD spectra of $(R)-4$ to the experimental VCD spectrum of (+)-4 (blue) (from Fig. 1). The population-weighted B3LYP/TZ2P IR and VCD spectra for each conformer $\mathbf{4 a}-\mathbf{c}$ are also shown. Fundamentals are numbered. Line shapes in calculated spectra $\operatorname{are~Lorentzian~}\left(\gamma=4 \mathrm{~cm}^{-1}\right)$.

$8000 \mathrm{rpm}$. The liquor was then continuously extracted with ethyl acetate for $24 \mathrm{~h}$ and the mycelium stirred vigorously with $\mathrm{MeOH}$. The organic phases were dried over $\mathrm{MgSO}_{4}$ and the solvent evaporated under vacuum.

\subsection{Microbial reductions of 2-acetyl-chromen-4-one}

The products from the residue were separated on a silica gel column (cyclohexane/ethyl acetate 35/65).

Baker's yeast: Yield of (-)-2-(1-hydroxyethyl)-chromen4-one, $(-)-1: 87 \% . R_{\mathrm{f}}=0.71 . \mathrm{Mp}=107.7^{\circ} \mathrm{C}(\mathrm{DSC}) .{ }^{1} \mathrm{H}$ NMR $(400.13 \mathrm{MHz}) \delta: 1.59$ (d, $\left.3 \mathrm{H}, \mathrm{CH}_{3}, J=6.7 \mathrm{~Hz}\right)$; 3.66 (br s, $1 \mathrm{H}$, exchangeable with $\left.\mathrm{D}_{2} \mathrm{O}\right) ; 4.74(\mathrm{q}, 1 \mathrm{H}$, $\mathrm{CHOH}, J=6.6 \mathrm{~Hz}) ; 6.52\left(\mathrm{~s}, 1 \mathrm{H}, \mathrm{H}_{3}\right) ; 7.30-7.41(\mathrm{~m}$, $2 \mathrm{H}, \mathrm{H}_{5}$ and $\left.\mathrm{H}_{6}\right) ; 7.56-7.65\left(\mathrm{~m}, 1 \mathrm{H}, \mathrm{H}_{7}\right) ; 8.10(\mathrm{dd}, 1 \mathrm{H}$, $\left.\mathrm{H}_{8}, J=1.6 \mathrm{~Hz}, J=7.9 \mathrm{~Hz}\right) .{ }^{13} \mathrm{C}$ NMR $(100.61 \mathrm{MHz})$ $\delta: 21.4\left(\mathrm{CH}_{3}\right) ; 67.1(\mathrm{CHOH}) ; 107.2(\mathrm{C}-3) ; 118.0(\mathrm{C}-8)$; 123.6 (Cq-b); 125.2 (C-6); 125.6 (C-5); 133.8 (C-7); 156.2 (Cq-a); 172.2 (C-2); 179.2 (C-4). MS (EI) $\mathrm{m} / \mathrm{z}$ : $190\left(\mathrm{M}^{+} \cdot\right) ; 175\left(\mathrm{M}-\mathrm{CH}_{3}\right)^{+} ; 145\left(\mathrm{M}-\mathrm{CHOH}-\mathrm{CH}_{3}\right)^{+}$.
$[\alpha]_{\mathrm{D}}^{25}=-60\left(c\right.$ 2.85, $\left.\mathrm{CHCl}_{3}\right)$; ee $>98 \%$. Anal. Calcd for $\mathrm{C}_{11} \mathrm{H}_{10} \mathrm{O}_{3}$ : C, 69.46; $\mathrm{H}, 5.30 ; \mathrm{O}, 25.24$. Found: $\mathrm{C}$, 69.37; H, 5.38.

Yamadazyma farinosa: Yield of (+)-2-(1-hydroxyethyl)chromen-4-one, $(+)-1: 60 \%$. Same physical constants and NMR spectra as those for $(-)-1 .[\alpha]_{\mathrm{D}}^{25}=+53(c$ $3.1, \mathrm{CHCl}_{3}$ ); ee $=89 \%$.

\subsection{Microbial reductions of 2-acetyl-6-bromo-chromen- 4-one}

The products from the residue were separated on a silica gel column (cyclohexane/ethyl acetate 50/50).

Baker's yeast: Yield (-)-6-bromo-2-(1-hydroxyethyl)chromen-4-one, $(-)-2: 67 \% . \quad R_{\mathrm{f}}=0.43 . \mathrm{Mp}=130.2^{\circ} \mathrm{C}$ (DSC). ${ }^{1} \mathrm{H}$ NMR $(400.13 \mathrm{MHz}) \delta: 1.60\left(\mathrm{~d}, 3 \mathrm{H}, \mathrm{CH}_{3}\right.$, $J=7.5 \mathrm{~Hz}) ; 3.90$ (s, $1 \mathrm{H}$, exchangeable with $\mathrm{D}_{2} \mathrm{O}$ ); $4.67-4.80(\mathrm{~m}, 1 \mathrm{H}, \mathrm{CHOH}) ; 6.51\left(\mathrm{~s}, 1 \mathrm{H}, \mathrm{H}_{3}\right) ; 7.34(\mathrm{~d}$, $\left.1 \mathrm{H}, \mathrm{H}_{8}, J=9.0 \mathrm{~Hz}\right) ; 7.73\left(\mathrm{dd}, 1 \mathrm{H}, \mathrm{H}_{7}, J=2.5 \mathrm{~Hz}\right.$, 
$J=9.0 \mathrm{~Hz}) ; 8.28\left(\mathrm{~d}, 1 \mathrm{H}, \mathrm{H}_{5}, J=2.5 \mathrm{~Hz}\right) .{ }^{13} \mathrm{C} \mathrm{NMR}$ $(100.61 \mathrm{MHz}) \quad \delta: 21.4\left(\mathrm{CH}_{3}\right) ; 67.0(\mathrm{CHOH}) ; 107.1$ (C-3); 118.6 (C-6); 120.0 (C-8); 124.9 (Cq-b); 128.2 (C5); 136.8 (C-7); 154.9 (Cq-a); 172.6 (C-2); 177.7 (C-4). MS (EI) $m / z: 268,270\left(\mathrm{M}^{+}\right) ; 225,227(\mathrm{M}-\mathrm{CHOH}-$ $\left.\mathrm{CH}_{3}\right)^{+\cdot} ; 146\left(\mathrm{M}-\mathrm{C}_{2} \mathrm{H}_{5} \mathrm{O}-\mathrm{Br}\right)^{+} ; 118 ; 77 .[\alpha]_{\mathrm{D}}^{25}=-54(c$ $2.45, \mathrm{CHCl}_{3}$ ); ee $>98 \%$. Anal. Calcd for $\mathrm{C}_{11} \mathrm{H}_{9} \mathrm{BrO}_{3}$ : C, 49.10; H, 3.37; O, 17.84. Found: C, 50.09; H, 3.37.

Yamadazyma farinosa: Yield of (+)-6-bromo-2-(1hydroxyethyl)-chromen-4-one, (+)-2: 70\%. Same physical constants and NMR spectra as those for (-)-2. $[\alpha]_{\mathrm{D}}^{25}=+54\left(c 1.6, \mathrm{CHCl}_{3}\right)$; ee $>98 \%$.

\subsection{Chemical reduction}

$( \pm)-1$ and $( \pm)-2$ were prepared by classical chemical reduction of the corresponding substrate by $\mathrm{NaBH}_{4} \cdot{ }^{20}$

\subsection{Acetylation of 1 and 2}

To a freshly distilled pyridine solution $(5 \mathrm{~mL})$ of chromen-4-one ( $1.5 \mathrm{mmol})$, acetic anhydride $(4.5 \mathrm{mmol}$, $750 \mu \mathrm{L}$ ) was added dropwise and the mixture stirred overnight at room temperature. To this solution was then added $20 \mathrm{~mL}$ of water and vigorous stirring maintained for $1 \mathrm{~h}$. The aqueous phase was extracted twice with diethyl ether. The organic phase was dried over $\mathrm{MgSO}_{4}$ and the solvent evaporated under vacuum. The crude product was purified on a silica gel column.

(i) ( \pm )-2-(1-Hydroxyacetyl-ethyl)-chromen-4-one, $( \pm)-3$ : $( \pm)-3$ was obtained from $( \pm)-1$. Eluent: cyclohexane/ethyl acetate $7 / 3$. Yield: $88 \% . R_{\mathrm{f}}=0.56 .{ }^{1} \mathrm{H}$ NMR (400.13 MHz) $\delta: 1.55(\mathrm{~d}, 3 \mathrm{H}, J=6.8 \mathrm{~Hz})$; $2.09(\mathrm{~s}, 3 \mathrm{H}) ; 5.65(\mathrm{q}, 1 \mathrm{H}, \mathrm{CHO}, J=6.8 \mathrm{~Hz}) ; 6.29$ (s, $\left.1 \mathrm{H}, \mathrm{H}_{3}\right) ; 7.33$ (td, $1 \mathrm{H}, J=1.1 \mathrm{~Hz}, J=7.0 \mathrm{~Hz}$ ); $7.39(\mathrm{~d}, 1 \mathrm{H}, J=8.4 \mathrm{~Hz}) ; 7.61(\mathrm{td}, 1 \mathrm{H}, J=1.7 \mathrm{~Hz}$, $J=7.0 \mathrm{~Hz}) ; 8.11(\mathrm{dd}, 1 \mathrm{H}, J=1.2 \mathrm{~Hz}, J=8.2 \mathrm{~Hz})$. ${ }^{13} \mathrm{C}$ NMR $(100.61 \mathrm{MHz}) \quad \delta: 18.6\left(\mathrm{CH}_{3}\right) ; 20.9$ $\left(\mathrm{CH}_{3}\right) ; 68.2$ (C-9); 108.1 (C-3); 118.0 (C-8); 123.9 (Cq-b); 125.3 (C-6); 125.8 (C-5); 133.8 (C-7); 156.2 (Cq-a); 166.6 (C-11); 169.6 (C-2); 178.1 (C-4).

(ii) (+)-2-(1-Hydroxyacetyl-ethyl)-chromen-4-one, (+)-3: (+)-3 was obtained from (+)-1. Yield: $90 \%$. Same physical constants and NMR spectra as in (i). $[\alpha]_{\mathrm{D}}^{25}=+100.8\left(c 1.0, \mathrm{CHCl}_{3}\right)$. Anal. Calcd for $\mathrm{C}_{13} \mathrm{H}_{12} \mathrm{O}_{4}$ : C, 67.23; H, 5.21; O, 27.56. Found: C, $67.15 ; \mathrm{H}, 5.24 ; \mathrm{O}, 27.61$

(iii) (-)-2-(1-Hydroxyacetyl-ethyl)-chromen-4-one, (-)3: (-)-3 was obtained from (-)-1. Yield: $85 \%$. Same physical constants and NMR spectra as those in (i). $[\alpha]_{\mathrm{D}}^{25}=-104.0\left(\mathrm{c} 1.2, \mathrm{CHCl}_{3}\right)$. Anal. Calcd for $\mathrm{C}_{13} \mathrm{H}_{12} \mathrm{O}_{4}$ : C, 67.23; H, 5.21; O, 27.56. Found: $\mathrm{C}, 67.37 ; \mathrm{H}, 5.15 ; \mathrm{O}, 27.48$.

(iv) ( \pm )-6-Bromo-2-(1-hydroxyacetyl-ethyl)-chromen-4one, $( \pm)-4$ : $( \pm)-4$ was obtained from $( \pm)-2$. Eluent: cyclohexane/ethyl acetate 6/4. Yield: $88 \%, R_{\mathrm{f}}=$ 0.62. $\mathrm{Mp}=75-76^{\circ} \mathrm{C} .{ }^{1} \mathrm{H}$ NMR $(400.13 \mathrm{MHz}) \delta$ : $1.54(\mathrm{~d}, 3 \mathrm{H}, J=6.8 \mathrm{~Hz}) ; 2.09(\mathrm{~s}, 3 \mathrm{H}) ; 5.63(\mathrm{q}, 1 \mathrm{H}$, $\mathrm{CHO}, J=6.6 \mathrm{~Hz}) ; 6.30(\mathrm{~s}, 1 \mathrm{H}) ; 7.24(\mathrm{~d}, 1 \mathrm{H}$, $J=9.0 \mathrm{~Hz}) ; 7.68(\mathrm{dd}, 1 \mathrm{H}, J=2.4 \mathrm{~Hz}, J=8.8 \mathrm{~Hz})$; $8.24(\mathrm{~d}, 1 \mathrm{H}, J=2.4 \mathrm{~Hz}) .{ }^{13} \mathrm{C}$ NMR $(100.61 \mathrm{MHz})$ $\delta: 18.6\left(\mathrm{CH}_{3}\right) ; 20.9\left(\mathrm{CH}_{3}\right) ; 68.1(\mathrm{C}-9) ; 108.2(\mathrm{C}-3)$; 118.8 (C-6); 120.0 (C-8); 125.2 (Cq-b); 128.4 (C-5); 136.8 (C-7); 154.9 (Cq-a); 167.0 (C-11); 171.9 (C2); 177.9 (C-4).

(v) (+)-6-Bromo-2-(1-hydroxyacetyl-ethyl)-chromen-4one, (+)-4: (+)-4 was obtained from (+)-2. Yield: 94\%. Same physical constants and NMR spectra as those in (iv). $[\alpha]_{\mathrm{D}}^{25}=+85.6\left(c 1.5, \mathrm{CHCl}_{3}\right)$. Anal. Calcd for $\mathrm{C}_{13} \mathrm{H}_{11} \mathrm{BrO}_{4}$ : C, 50.19; H, 3.56; O, 20.57. Found: C, 50.12; H, 3.50; O, 20.58.

(vi) (-)-6-Bromo-2-(1-hydroxyacetyl-ethyl)-chromen-4one, (-)-4: (-)-4 was obtained from (-)-2. Yield: $88 \%$. Same physical constants and NMR spectra as in (iv). $[\alpha]_{\mathrm{D}}^{25}=-85.6\left(c 0.9, \mathrm{CHCl}_{3}\right)$. Anal. Calcd for $\mathrm{C}_{13} \mathrm{H}_{11} \mathrm{BrO}_{4}$ : C, 50.19; H, 3.56; O, 20.57. Found: C, 50.31; H, 3.48; O, 20.46.

\subsection{IR and VCD spectra}

IR and VCD spectra of $\mathrm{CCl}_{4}$ solutions of $( \pm)-,(+)$ - and $(-)-3$ and $( \pm)-,(+)-$ and $(-)-4$ were measured using Nicolet MX-1 and Bomem/BioTools Chiral $I R$ spectrometers, respectively. Concentrations were $\sim 0.064 \mathrm{M}$ for all solutions of 3 and $\sim 0.074 \mathrm{M}$ for all solutions of 4. Resolutions were $1 \mathrm{~cm}^{-1}$ (IR) and $4 \mathrm{~cm}^{-1}$ (VCD). The cell pathlength was $109 \mu$. VCD acquisition times were $1 \mathrm{~h}$. Baselines for the VCD spectra of the (+)and (-)-isomers of $\mathbf{3}$ and $\mathbf{4}$ were the VCD spectra of the corresponding $( \pm)$ samples. After conversion to VCD spectra in $\Delta \epsilon$ units, VCD spectra of (+)-3 and $(+)-4$ were normalised to the ee's of the $(-)-3$ and $(-)$ 4 samples by multiplication by $[\alpha]_{D}(-) /[\alpha]_{D}(+)$ for 3 and $4 .[\alpha]_{D}$ values were: $(+)-3,90.7 ;(-)-3,-100.5 ;(+)-$ 4, 84.8; (-)-4, -95.5. Finally, 'half-difference' VCD spectra $\frac{1}{2}[\Delta \varepsilon(+)-\Delta \varepsilon(-)]$, were calculated for $\mathbf{3}$ and $\mathbf{4}$; these spectra are those presented in Figure 1.

\subsection{DFT calculations}

All DFT calculations were carried out using GAUSSIAN 98 or GAUSSIAN $03 .{ }^{10}$ As in prior work, ${ }^{11-17}$ the functionals B3LYP and B3PW91 and the basis sets $6-31 \mathrm{G}^{*}$ and TZ2P were used. Calculations of vibrational frequencies, dipole strengths and rotational strengths are carried out within the harmonic approximation. Atomic axial tensors (AATs) are calculated using gauge-invariant atomic orbitals (GIAOs), ${ }^{8,9}$ ensuring origin-independence of the rotational strengths obtained thence. IR and VCD spectra are obtained from frequencies, dipole strengths and rotational strengths using Lorentzian band shapes. ${ }^{23,24}$

\section{Acknowledgments}

This work has been supported by NSF grant (to P.J.S.) CHE-0209957. We are also grateful to the USC High Performance Computing and Communications (HPCC) Center for computer time and to Dr. H. Veschambre and Dr. G. Baziard-Mouysset for their help in the preparation of the substrates and derivatives of chromen-4one. 


\section{References}

1. Stephens, P. J.; Lowe, M. A. Annu. Rev. Phys. Chem. 1985, 36, 213-241.

2. Stephens, P. J. Encyclopedia of Spectroscopy and Spectrometry; Academic: London, 2000, pp 2415-2421.

3. Stephens, P. J.; Devlin, F. J. Chirality 2000, 12, 172 179 .

4. Stephens, P. J.; Devlin, F. J.; Aamouche, A. In Chirality: Physical Chemistry; Hicks, J. M., Ed.; ACS Symposium Series, 2002; Vol. 810, Chapter 2, pp 18-33.

5. Stephens, P. J. Computational Medicinal Chemistry for Drug Discovery. In Bultinck, P., de Winter, H., Langenaecker, W., Tollenaere, J., Eds.; Dekker: New York, 2003; Chapter 26, pp 699-725.

6. Stephens, P. J. J. Phys. Chem. 1985, 89, 748-752.

7. Stephens, P. J. J. Phys. Chem. 1987, 91, 1712-1715.

8. Cheeseman, J. R.; Frisch, M. J.; Devlin, F. J.; Stephens, P. J. Chem. Phys. Lett. 1996, 252, 211-220.

9. Stephens, P. J.; Ashvar, C. S.; Devlin, F. J.; Cheeseman, J. R.; Frisch, M. J. Mol. Phys. 1996, 89, 579-594.

10. GAUSSIAN 98/03, Gaussian Inc., www.gaussian.com.

11. Aamouche, A.; Devlin, F. J.; Stephens, P. J. J. Am. Chem. Soc. 2000, 122, 2346-2354.

12. Aamouche, A.; Devlin, F. J.; Stephens, P. J.; Drabowicz, J.; Bujnicki, B.; Mikolajczyk, M. Chem. Eur. J. 2000, 6, $4479-4486$

13. Aamouche, A.; Devlin, F. J.; Stephens, P. J.; Superchi, S.; Donnoli, M. I.; Rosini, C. J. Org. Chem. 2001, 66, 36713677.

14. Devlin, F. J.; Stephens, P. J.; Scafato, P.; Superchi, S.; Rosini, C. Tetrahedron: Asymmetry 2001, 12, 15511558 .

15. Devlin, F. J.; Stephens, P. J.; Scafato, P.; Superchi, S.; Rosini, C. Chirality 2002, 14, 400-406

16. Devlin, F. J.; Stephens, P. J.; Oesterle, C.; Wiberg, K. B.; Cheeseman, J. R.; Frisch, M. J. J. Org. Chem. 2002, 67, 8090-8096

17. Cerè, V.; Peri, F.; Pollicino, S.; Ricci, A.; Devlin, F. J.; Stephens, P. J.; Gasparrini, F.; Rompietti, R.; Villani, C. J. Org. Chem. 2005, 70, 664669 .
18. Besse, P.; Baziard-Mouysset, G.; Boubekeur, K.; Palvadeau, P.; Veschambre, H.; Payard, M.; Mousset, G. Tetrahedron: Asymmetry 1999, 10, 4745 4754.

19. Devlin, F. J.; Stephens, P. J.; Besse, P. J. Org. Chem., in press.

20. Payard, M. Bull. Soc. Chim. Fr. 1973, 2392-2398.

21. Ikeda, H.; Sato, E.; Sugai, T.; Ohta, H. Tetrahedron 1996, $52,8113-8122$

22. Ohtsuka, Y.; Katoh, O.; Sugai, T.; Ohta, H. Bull. Chem. Soc. Jpn. 1997, 70, 483-491.

23. Devlin, F. J.; Stephens, P. J.; Cheeseman, J. R.; Frisch, M. J. J. Phys. Chem. 1997, 101, 6322-6333.

24. Devlin, F. J.; Stephens, P. J.; Cheeseman, J. R.; Frisch, M. J. J. Phys. Chem. 1997, 101, 9912-9924.

25. Stephens, P. J.; Devlin, F. J.; Cheeseman, J. R.; Frisch, M J.; Bortolini, O.; Besse, P. Chirality 2003, 15, S57-S64.

26. Ashvar, C. S.; Stephens, P. J.; Eggimann, T.; Wieser, H. Tetrahedron: Asymmetry 1998, 9, 1107-1110.

27. Ashvar, C. S.; Devlin, F. J.; Stephens, P. J.; Bak, K. L.; Eggimann, T.; Wieser, H. J. Phys. Chem. A 1998, 102, 6842-6857.

28. Devlin, F. J.; Stephens, P. J. J. Phys. Chem. A 1999, 103, 527-538.

29. Ashvar, C. S.; Devlin, F. J.; Stephens, P. J. J. Am. Chem. Soc. 1999, 121, 2836-2849.

30. Devlin, F. J.; Stephens, P. J. J. Am. Chem. Soc. 1999, 121, 7413-7414

31. Aamouche, A.; Devlin, F. J.; Stephens, P. J. J. Am. Chem. Soc. 2000, 122, 7358-7367.

32. Devlin, F. J.; Stephens, P. J.; Scafato, P.; Superchi, S.; Rosini, C. J. Phys. Chem. A 2002, 106, 10510-10524.

33. Finley, J. W.; Stephens, P. J. J. Mol. Struct. (Theochem) 1995, 357, 225-235.

34. Devlin, F. J.; Stephens, P. J.; Besse, P., in preparation.

35. Flack, H. D. Acta Crystallogr., Sect. A 1983, 39, 876-881.

36. Flack, H. D.; Bernardinelli, G. J. Appl. Crystallogr. 2000, 33, 1143-1148.

37. Nafie, L. A.; Keiderling, T. A.; Stephens, P. J. J. Am Chem. Soc. 1976, 98, 2715-2723.

38. Urbanová, M.; Setnička, V.; Devlin, F. J.; Stephens, P. J J. Am. Chem. Soc., submitted for publication. 